\title{
Evaluación de la Integridad Acrosomal en Espermatozoides Epididimarios de Alpaca mediante Citometría de Flujo
}

\author{
Evaluation of Acrosome Integrity in Epidydimal Alpaca Sperm by \\ Flow CyTOMETRY
}

\author{
Alejandra Ugarelli ${ }^{1}$, Shirley Evangelista-Vargas ${ }^{1}$, Alexei Santiani ${ }^{1,2,3}$
}

\section{Resumen}

\begin{abstract}
El objetivo del presente trabajo fue determinar el porcentaje de integridad acrosomal en espermatozoides epididimarios de alpaca utilizando Arachis hypogaea (PNA) y Pisum sativum (PSA), conjugadas con isoticianato de fluoresceína (FITC). Se recolectaron 45 testículos de alpaca, obtenidos del Camal Municipal de Ninacaca, provincia de Pasco (Perú), y se utilizaron 29 muestras recuperadas de la cola del epidídimo con motilidad mayor de $30 \%$ y concentración mayor de $50 \times 10^{6}$ espermatozoides $/ \mathrm{ml}$. Los espermatozoides fueron suspendidos con $1 \mathrm{ml}$ de solución Tris base, se lavaron por centrifugación a 600 $g$ por 8 min y los pellets fueron resuspendidos en $300 \mu \mathrm{l}$ de PBS. Cada muestra fue dividida en dos alícuotas e incubadas por $8 \mathrm{~min}$ a $38^{\circ} \mathrm{C}$ con FITC-PNA $(0.5 \mu \mathrm{g} / \mathrm{ml}) \mathrm{o}$ FITC-PSA $(2.5 \mu \mathrm{g} / \mathrm{ml})$, junto con un marcador de vitalidad (yoduro de propidio [PI], 0.5 $\mu \mathrm{g} / \mathrm{ml})$. Las muestras fueron evaluadas mediante citometría de flujo, utilizando un láser de excitación de $488 \mathrm{~nm}$ y canales detectores de emisión de fluorescencia de 505-560 nm (Canal 02 para FITC) y de $642-740 \mathrm{~nm}$ (Canal 05 para PI). Los espermatozoides que emitieron fluorescencia verde en el Canal 02 fueron considerados con daño acrosomal, mientras que los que emitieron fluorescencia roja en el Canal 05 fueron considerados muertos. Se obtuvo $59.17 \pm 4.84$ y $61.13 \pm 4.35 \%$ de espermatozoides vivos con integridad acrosomal para FITC-PNA y FITC-PSA, respectivamente. Los resultados presentan un indicador de la integridad acrosomal en espermatozoides epididimarios de alpaca, que podría constituir una base para el estudio de la fisiología espermática en esta especie.
\end{abstract}

Palabras clave: alpaca, espermatozoide, acrosoma, FITC-PSA, FITC-PNA, citometría de flujo

\footnotetext{
${ }^{1}$ Laboratorio de Biotecnología Reproductiva y Celular, Facultad de Ciencias Veterinarias y Biológicas, Universidad Científica del Sur, Lima, Perú

${ }^{2}$ Laboratorio de Reproducción Animal, Facultad de Medicina Veterinaria, Universidad Nacional Mayor de San Marcos, Lima, Perú

${ }^{3}$ E-mail: asantiani@hotmail.com
}

Recibido: 21 de julio de 2016

Aceptado para publicación: 11 de noviembre de 2016 
The aim of this study was to determine the percentage of epidydimal sperm acrosome integrity using alpaca Arachis hypogaea (PNA) and Pisum sativum (PSA), combined with fluorescein isothiocyanate (FITC). Testicles $(\mathrm{n}=45)$ were obtained at Ninacaca municipal slaughterhouse (Pasco, Peru). Only 29 samples with motility higher than $30 \%$ and concentration higher than $50 \times 10^{6} \mathrm{sperm} / \mathrm{ml}$ were used. Sperm from cauda epididymis were recovered with $1 \mathrm{ml}$ of Tris base solution, and then, washed by centrifugation at $600 \mathrm{~g}$ for $8 \mathrm{~min}$ and pellets were re-suspended in $300 \mu 1$ of PBS. Each sample was divided into two aliquots and incubated for $8 \mathrm{~min}$ at $38^{\circ} \mathrm{C}$ with FITC-PNA $(0.5 \mu \mathrm{g} / \mathrm{ml})$ or FITC-PSA $(2.5 \mu \mathrm{g} /$ $\mathrm{mL}$ ) together with propidium iodide (PI, $0.5 \mu \mathrm{g} / \mathrm{ml}$ ) as a viability marker. Samples were evaluated by flow cytometry using a laser excitation $488 \mathrm{~nm}$ and emission detector channels 505-560 nm fluorescence (channel 02 for FITC) and 642-740 nm (Channel 05 for $\mathrm{PI}$ ). Sperm emitting green fluorescence on Channel 02 were considered with acrosome damage while sperm emitting red fluorescence on Channel 05 were considered dead. The results showed $59.17 \pm 4.84$ and $61.13 \pm 4.35 \%$ of live sperm with acrosome integrity when using FITC-PNA and FITC-PSA respectively. These results are an indicator of epididymal sperm acrosome integrity in alpaca and can provide the basis for studying sperm physiology in this specie.

Key words: alpaca, spermatozoa, acrosome, FITC-PSA, FITC-PNA, flow cytometry

\section{INTRODUCCIÓN}

El acrosoma es una organela membranosa de doble capa ubicada en la parte apical de la cabeza espermática, que contiene distintas enzimas hidrolíticas, como la hialuronidasa y la acrosina. La determinación de la integridad acrosomal es uno de los parámetros espermáticos de importancia debido a su papel en la reacción acrosomal (RA). La RA es un proceso exocitótico que consiste en la fusión del acrosoma con la membrana plasmática, resultando en la exposición y liberación del contenido acrosomal al medio extracel ular (Ramal ho-Santos et al., 2002), permitiendo que se realice la fecundación del ovocito. La liberación del contenido acrosomal se lleva a cabo cuando el espermatozoide entra en contacto con mecanismos de señalización que se encuentran en la zona pelúcida (Harrison, 1998) y está mediado por la progesterona (Patrat et al., 2000), además de estar regulado por el incremento intracelular de calcio.
Existen distintos inductores in vitro que se utilizan para la reacción acrosomal (Patrat et al., 2000) siendo el más conocido el Calcio ionóforo A23187 (Carretero et al., 2015). Este trabaja mediante el flujo de iones de $\mathrm{Ca}^{+2}$ $\mathrm{y} \mathrm{K}^{+}$, que es clave en el diálogo molecular que se establece entre el espermatozoide, su medio ambiente y el ovocito, tanto en los procesos de maduración como de capacitación espermática para la reacción acrosomal (Cardona et al., 2006).

Existen diversas técnicas para la evaluación de la integridad acrosomal, entre ellas la microscopía de campo claro, microscopía de fluorescencia y citometría de flujo. Utilizando microscopía en alpacas, Banda et al. (2010) y Santiani et al. (2005) trabajaron la técnica de doble tinción (azul tripán y giemsa) para determinar de manera conjunta la integridad acrosomal y la viabilidad espermática. En llamas, Fumuso et al. (2015) utilizaron la técnica de triple tinción (azul tripán, rojo neutro-ácido clorhídrico y giemsa) como una técnica confiable para determinar la presencia 
acrosomal. Asimismo, para microscopía de fluorescencia se utilizan fluorocromos como el isoticianato de fluoresceína (FITC) conjugado con lectinas, que tienen afinidad por el acrosoma, donde FITC-PNA se une a los terminales $\beta$-galactosa que se encuentran dentro de la membrana acrosomal externa (Silva et al., 2006; Hernández et al., 2012), mientras que FITC-PSA se une a glucoproteínas que se encuentran en la matriz acrosomal (Silva et al., 2006; Celeghini et al., 2010). Al haber daño en la membrana acrosomal, las lectinas pueden unirse a su zona de anclaje, reflejándose como fluorescencia de color verde. Estas lectinas han sido empleadas para la evaluación acrosomal en espermatozoides de humano (Risopatron et al., 2001), porcino (Siciliano et al., 2008), ovino (Celeghini et al., 2010) y conejo (Hernández et al., 2012).

Estas técnicas son de baja precisión ya que dependen en gran medida de la experiencia del evaluador. Además, son laboriosas y demandantes de tiempo (Gillan et al., 2005). Por el contrario, la citometría de flujo permite una evaluación más segura y no es dependiente del laboratorista sino del software de análisis del citómetro, permitiendo la evaluación de mayor número de eventos, generalmente en un rango de 8000-20000 espermatozoides, en comparación con los 200 espermatozoides que se observa generalmente en los análisis con microscopía, dado que es un conteo automatizado, objetivo y rápido de un flujo celular mediante la detección de intensidades de fluorescencia (Gillan et al., 2005).

La evaluación de la viabilidad e integridad acrosomal mediante citometría de flujo ha sido reportada en alpacas (Cheuquemán et al., 2013) y llamas (Carretero et al., 2015), utilizando FITC-PSA/PI y FITC-PNA/PI, respectivamente. Sin embargo, recientemente, el uso de citometría de flujo en conjunto con un sistema analizador de imágenes ha cuestionado los resultados obtenidos mediante citometría tradicional. En ese sentido, Ugarelli et al. (2015) reportan que las concentracio- nes ideales de FITC-PNA y FITC-PSA para la valoración de la integridad acrosomal son muy inferiores a las descritas para microscopía de fluorescencia y citometría tradicional. Por lo tanto, el objetivo del presente trabajo fue determinar el porcentaje de integridad acrosomal en espermatozoides epididimarios de alpaca, utilizando Arachis hypogaea (PNA) y Pisum sativum (PSA), conjugadas con FITC y evaluadas mediante citometría de flujo con sistema analizador de imágenes.

\section{Materiales y Métodos}

\section{Lugar de Estudio}

El estudio se realizó en el Laboratorio de Biotecnología Reproductiva y Celular, Facultad de Ciencias Veterinarias y Biológicas de la Universidad Científica del Sur (UCSUR) y en el Laboratorio de Reproducción Animal, Facultad de Medicina Veterinaria, Universidad Nacional Mayor de San Marcos, Lima.

\section{Muestras Biológicas}

Se obtuvieron 45 testículos de alpaca del camal municipal del distrito de Ninacaca, en la provincia de Pasco, Perú, entre setiembre y diciembre de 2015. Los testículos fueron lavados con suero fisiológico a $5^{\circ} \mathrm{C}$ y se les retiró la túnica vaginal. Se colocaron en frascos con suero fisiológico a $5^{\circ} \mathrm{C}$ y se llevaron a Lima (20 horas aproximadamente) en cajas transportadoras con refrigerantes a $5^{\circ} \mathrm{C}$, según lo descrito por Banda et al. (2010).

En el laboratorio, los testículos fueron lavados con PBS a $38{ }^{\circ} \mathrm{C}$, se separaron las colas del epidídimo con tijera y se colocaron en placas petri. En las placas se colocó $1 \mathrm{ml}$ de medio TRIS (Tris $2.71 \mathrm{~g}$, ácido cítrico 1.4 $\mathrm{g}$ y fructuosa $1 \mathrm{~g}$ csp $100 \mathrm{ml}$ ) y con la ayuda de una pinza y una hoja de bisturí se les realizaron pequeños cortes y se prensaron suavemente con el fin de liberar los esperma- 
tozoides. Se recuperó $1 \mathrm{ml}$ de cada muestra y se evaluó la motilidad (\%) y concentración espermática (espermatozoides $/ \mathrm{ml}$ ). Al final, solo se trabajaron 29 muestras con motilidad mayor de $30 \%$ y con una concentración mayor de $50 \times 10^{6}$ espermatozoides $/ \mathrm{ml}$.

\section{Integridad del Acrosoma}

Cada muestra fue centrifugada a $600 \mathrm{~g}$ por 8 min en dos oportunidades y reconstituida en $300 \mu \mathrm{L}$ de PBS. La evaluación de la viabilidad e integridad del acrosoma se hizo mediante los siguientes procedimientos:

- FITC-PNA/PI: se tomó $100 \mu 1$ de cada muestra y se incubó por 8 minutos a $38^{\circ} \mathrm{C}$ con $0.5 \mu 1$ de solución Stock de FITCPNA $(100 \mu \mathrm{g} / \mathrm{ml})$ para obtener una concentración de $0.5 \mu \mathrm{g} / \mathrm{ml}$. Se adicionó $0.5 \mu 1$ de solución Stock de PI $(1 \mathrm{mg} / \mathrm{ml})$ para llegar a una concentración final de $5 \mu \mathrm{g} / \mathrm{ml}$.

- $\quad$ FITC-PSA/PI: se tomó $100 \mu 1$ de cada muestra y se incubó por 8 minutos a $38^{\circ} \mathrm{C}$ con $2.5 \mu 1$ de solución Stock de FITCPSA $(100 \mu \mathrm{g} / \mathrm{ml})$ para obtener una concentración de $2.5 \mu \mathrm{g} / \mathrm{ml}$ de FITC-PSA. Se adicionó $0.5 \mu 1$ de solución Stock de PI $(1 \mathrm{mg} / \mathrm{ml})$ para llegar a una concentración final de $5 \mu \mathrm{g} / \mathrm{ml}$.

Como control positivo de FITC-PSA y FITC-PNA, se indujo la reacción acrosomal incubando $\left(38^{\circ} \mathrm{C}\right.$ por $\left.60 \mathrm{~min}\right) 100 \mu \mathrm{l}$ de muestra con $1 \mu 1$ de ionóforo de calcio A23187 (Stock $1 \mathrm{mM}$ ) para llegar a una concentración final de $10 \mu \mathrm{M}$. Asimismo, como control positivo de PI, $100 \mu \mathrm{l}$ de muestra fue congelada a $0{ }^{\circ} \mathrm{C}$ por 60 min y luego incubada con PI a una concentración final de $5 \mu \mathrm{g} / \mathrm{ml}$.

\section{Citometría de flujo con Sistema Analiza- dor de Imágenes}

Se utilizó el citómetro de flujo FlowSight (Amnis, Seattle, EEUU), equipado con un sistema analizador de imágenes. El software de adquisición usado fue INSPIRE ${ }^{\circledR} \mathrm{v}$. 100.3.218.0 (Amnis, Seattle, EEUU) y el software para analizar los datos fue IDEAS ${ }^{\circledR} \mathrm{v}$.
6.2 (Amnis, Seattle, EEUU). Se adquirieron 10 mil eventos compatibles con espermatozoides según su tamaño y proporción largo/ancho. Los eventos fueron excitados con un láser de longitud de onda de 488 $\mathrm{nm}$ y potencia de $20 \mathrm{~mW}$. La evaluación de la intensidad de fluorescencia de FITC-PNA y FITC-PSA se realizó utilizando un canal de detección de 505 a $560 \mathrm{~nm}$ (Ch02), mientras que la intensidad de fluorescencia de PI se realizó utilizando un canal de detección de 642 a $740 \mathrm{~nm}$ (Ch05). Adicionalmente, en cada grupo se registraron imágenes para comprobar si las lectinas marcaron la región acrosomal.

Los espermatozoides fueron clasificados en cuatro poblaciones celulares: a) espermatozoides vivos con integridad acrosomal (FITC negativo, PI negativo), b) espermatozoides vivos con daño acrosomal (FITC positivo, PI negativo), c) espermatozoides muertos con integridad acrosomal (FITC negativo, PI positivo) y d) espermatozoides muertos con daño acrosomal (FITC positivo, PI positivo).

\section{Análisis Estadístico}

Para determinar si el porcentaje de espermatozoides vivos, espermatozoides con integridad acrosomal y espermatozoides vivos con integridad acrosomal cursaban con una distribución normal, se usó el test de Kolmogorov-Smirnov (Test K-S). Para determinar la correlación entre el porcentaje de espermatozoides vivos y el porcentaje de espermatozoides vivos con integridad acrosomal incubados con FITC-PNA y FITCPSA, se usó el coeficiente de correlación de Pearson. Para determinar la correlación entre espermatozoides con integridad acrosomal incubados con FITC-PNA y FITC-PSA, se utilizaron los coeficientes de correlación de Pearson y Spearman, dependiendo si seguían la distribución normal. Todos los parámetros (promedio, mediana, desviación estándar, intervalo de confianza y coeficiente de variación) y análisis estadísticos fueron realizados utilizando el software GraphPad Prism ${ }^{\circledR}$ v. 3.0 (San Diego, EEUU). 
(A) FITC-PNA/PI

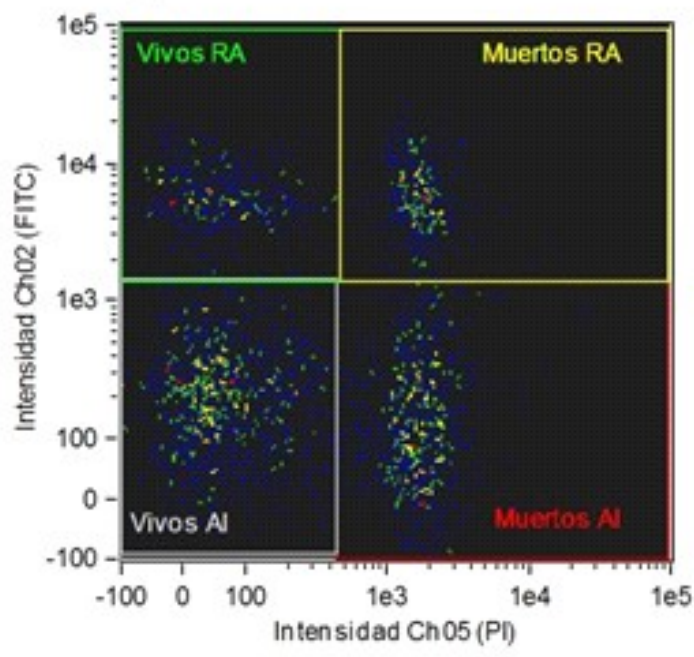

(B) FITC-PSAVPI

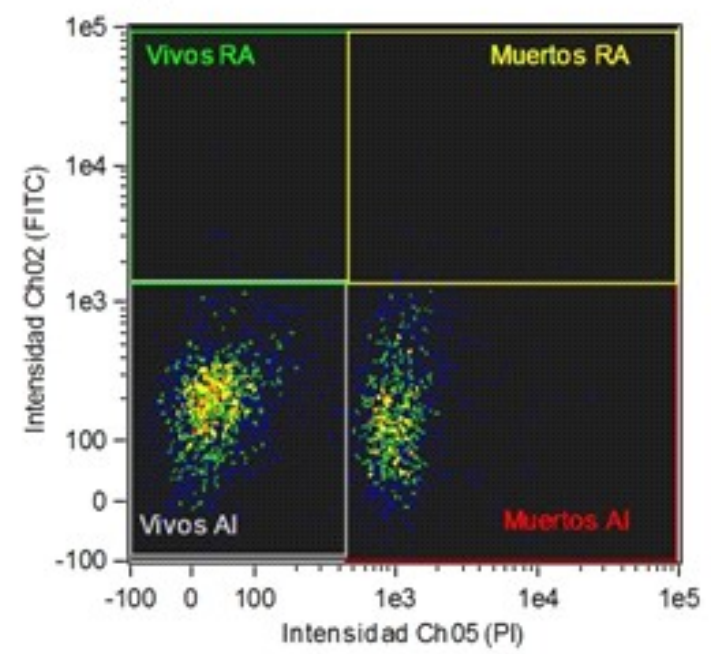

Figura 1. Diagrama de puntos (Dot Plot) representativo para (A) FITC-PNA/PI y (B) FITCPSA/PI. Se observan cuatro poblaciones claramente diferenciadas (Cuadrante inferior izquierdo: espermatozoides vivos con acrosoma intacto; Cuadrante inferior derecho: espermatozoides muertos con acrosoma intacto; Cuadrante superior izquierdo: espermatozoides vivos con reacción acrosomal; Cuadrante superior derecho: espermatozoides muertos con reacción acrosomal. En el eje X se observa la intensidad del canal Ch05 (PI) y en el eje Y la intensidad del canal Ch02 (FITC)

\section{Resultados}

Los datos obtenidos de las muestras evaluadas usando FITC-PNA/PI se presentan en el Cuadro 1. El promedio porcentual de espermatozoides vivos, espermatozoides con integridad acrosomal y espermatozoides vivos con integridad acrosomal fue de 60.43 $\pm 4.87,93.30 \pm 2.98$ y $59.17 \pm 4.84$ (IC $95 \%$ ). En la Figura 1 se ve un Dot Plot representativo de las muestras obtenidas con FITCPNA/PI y FITC-PSA/PI.

En el Cuadro 2 se observan los datos obtenidos usando FITC-PSA/PI. El promedio porcentual de espermatozoides vivos, espermatozoides con integridad acrosomal y espermatozoides vivos con integridad acrosomal fue de $63.38 \pm 4.61,95.19 \pm 2.33$ y $61.13 \pm 4.35$ (IC 95\%). En la Figura $2 \mathrm{se}$ muestras fotografías obtenidas en cada población con FITC-PNA/PI y en la Figura 3 se muestran fotografías obtenidas de cada población con FITC-PSA/PI.

En el Cuadro 3 se observa la correlación de los datos obtenidos por incubación con FITC-PNA/PI y FITC-PSA/PI. Al comparar las lectinas FITC-PNA y FITC-PSA, se encontró que los porcentajes de integridad acrosomal, viabilidad espermática y viabilidad e integridad acrosomal presentaron coeficientes significativos y moderados.

\section{Discusión}

Este es el primer reporte que describe los porcentajes de integridad acrosomal en espermatozoides obtenidos del epidídimo en alpaca utilizando isoticianato de fluoresceína (FIT) conjugado con Arachys hypogaea (PNA) y con Pisum sativum (PSA) asociados con yoduro de propidio (PI) y con lectura en citometría de flujo con analizador de imágenes. 
Cuadro 1. Evaluación de espermatozoides epididimarios vivos, espermatozoides con integridad acrosomal y espermatozoides vivos con integridad acrosomal de alpaca utilizando la lectina Arachis hypogaea (PNA) conjugada con isotiocianato de fluoresceína (FITC-PNA) y yoduro de propidio (PI)

\begin{tabular}{lccc}
\hline & $\begin{array}{c}\text { Espermatozoides } \\
\text { vivos }\end{array}$ & $\begin{array}{c}\text { Espermatozoides } \\
\text { con integridad } \\
\text { acrosomal }\end{array}$ & $\begin{array}{c}\text { Espermatozoides } \\
\text { vivos con } \\
\text { integridad } \\
\text { acrosomal }\end{array}$ \\
\hline Promedio (\%) & 60.43 & 93.30 & 59.17 \\
Mediana & 63.20 & 95.90 & 60.20 \\
Desviación estándar & 13.38 & 8.19 & 13.30 \\
Intervalo de confianza & 4.87 & 2.98 & 4.84 \\
Coeficiente de variación (\%) & 22.14 & 8.78 & 22.47 \\
Test KS & 0.118 & 0.27 & 0.09 \\
P & $\mathrm{p}>0.10$ & 0.02 & $\mathrm{p}>0.10$ \\
Pasó test de normalidad & Sí & No & Sí \\
$(0.05)$ & & & \\
\hline
\end{tabular}

Cuadro 2. Evaluación de espermatozoides epididimarios vivos, espermatozoides con integridad acrosomal y espermatozoides vivos con integridad acrosomal de alpaca utilizando la lectina Pisum sativum y conjugada con isotiocianato de fluoresceína (FITC-PSA) y yoduro de propidio (PI)

\begin{tabular}{lccc}
\hline & $\begin{array}{c}\text { Espermatozoides } \\
\text { vivos }\end{array}$ & $\begin{array}{c}\text { Espermatozoides } \\
\text { con integridad } \\
\text { acrosomal }\end{array}$ & $\begin{array}{c}\text { Espermatozoides } \\
\text { vivos con } \\
\text { integridad } \\
\text { acrosomal }\end{array}$ \\
\hline Promedio (\%) & 63.38 & 95.19 & 61.13 \\
Mediana & 35.00 & 97.80 & 63.90 \\
Desviación estándar & 12.88 & 6.40 & 11.94 \\
Intervalo de confianza & 4.61 & 2.33 & 4.35 \\
Coeficiente de variación (\%) & 20.33 & 6.73 & 19.53 \\
Test KS & 0.09 & 0.27 & 0.11 \\
P & $\mathrm{p}>0.10$ & 0.02 & $\mathrm{p}>0.10$ \\
Pasó test de normalidad (0.05) & $\mathrm{Sí}$ & $\mathrm{No}$ & Sí \\
\hline
\end{tabular}




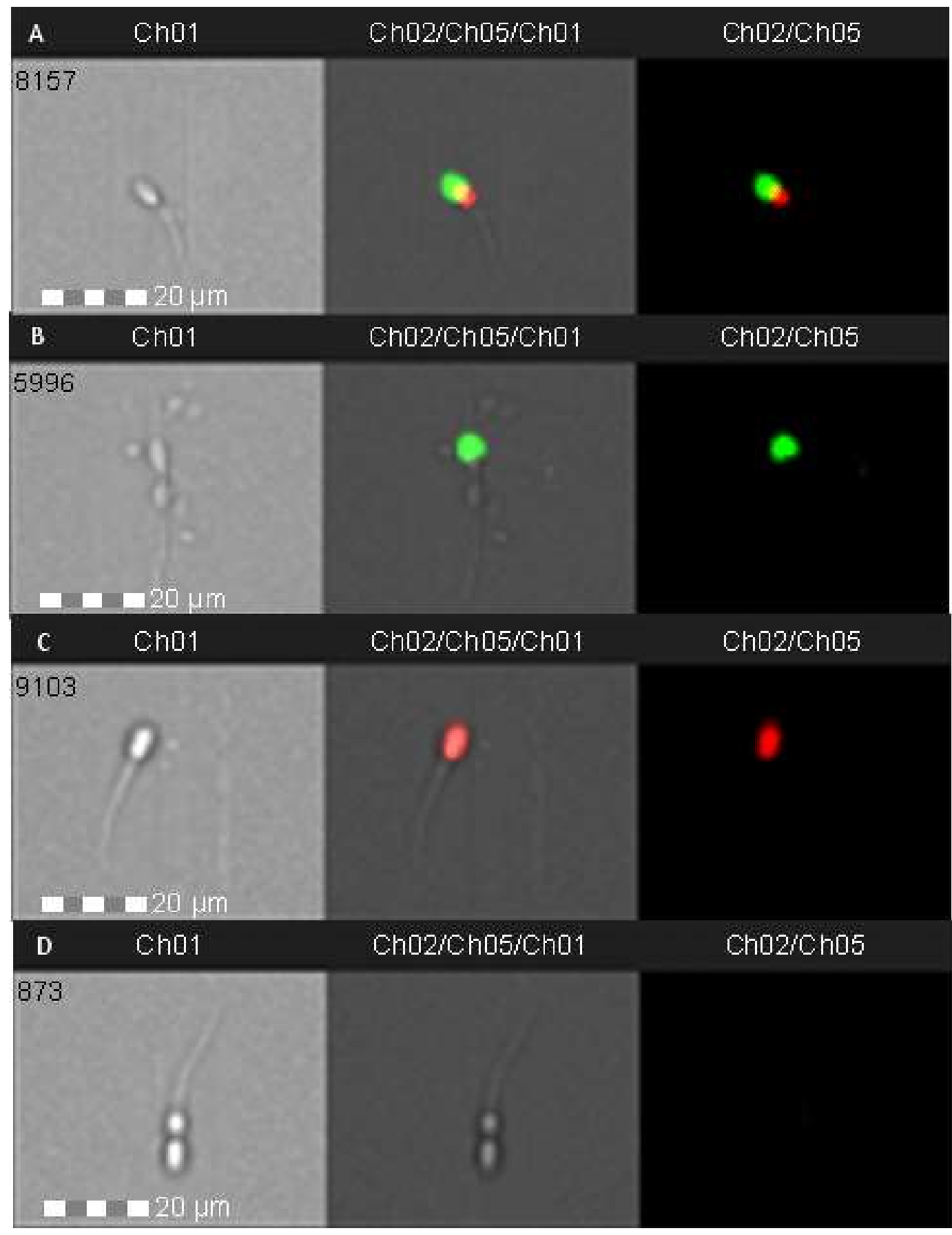

Figura 2. Espermatozoides epididimarios de alpaca incubados con Arachys hypogaea conjugado con isoticianato de fluoresceína (FITC-PNA y yoduro de propidio (PI); observados en campo claro (Ch01), combinación de campo claro y fluorescencia (Ch01/ $\mathrm{Ch} 02 / \mathrm{Ch} 05)$ y con fluorescencia (Ch02/Ch05). Patrones observados luego de incubar espermatozoides de alpaca con FITC-PNA/PI: A) espermatozoide muerto con reacción acrosomal. B) espermatozoide vivo con reacción acrosomal. C) espermatozoide muerto con acrosoma intacto. D) espermatozoide vivo con acrosoma intacto 


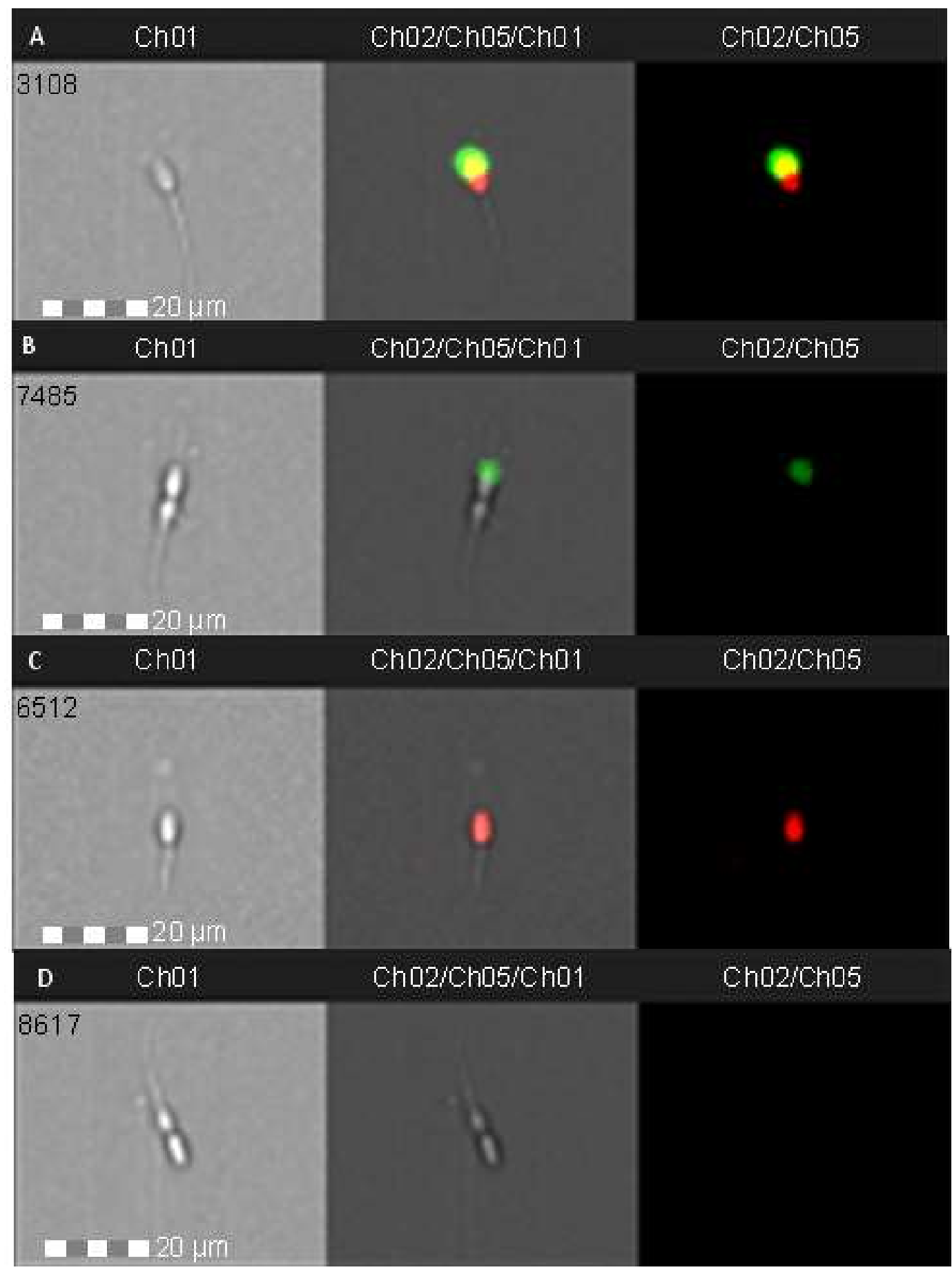

Figura 3. Espermatozoides epididimarios de alpaca incubados con Pisum sativum conjugado con isoticianato de fluoresceína (FITC-PSA) y yoduro de propidio (PI), observados en campo claro (Ch01), combinación de campo claro y fluorescencia (Ch01/Ch02/ Ch05) y con fluorescencia (Ch02/Ch05). Patrones observados luego de incubar espermatozoides de alpaca con FITC-PSA/PI: A) espermatozoide muerto con reacción acrosomal. B) espermatozoide vivo con reacción acrosomal. C) espermatozoide muerto con acrosoma intacto. D) espermatozoide vivo con acrosoma intacto 
Cuadro 3. Coeficientes de correlación entre porcentaje de espermatozoides vivos, porcentaje de espermatozoides con integridad acrosomal y porcentaje de espermatozoides vivos con integridad acrosomal, utilizando las lectinas FITCPNA y FITC-PSA junto con yoduro de propidio (PI)

\begin{tabular}{|c|c|c|c|}
\hline & $\begin{array}{l}\text { Vivos con } \\
\text { FITC-PNA }\end{array}$ & $\begin{array}{l}\text { Con integridad } \\
\text { acrosomal con } \\
\text { FITC-PNA }\end{array}$ & $\begin{array}{l}\text { Vivos con } \\
\text { integridad } \\
\text { acrosomal con } \\
\text { FITC-PNA }\end{array}$ \\
\hline Vivos con FITC-PSA & $\begin{array}{l}0.6296^{1} \\
\mathrm{P}=0.003\end{array}$ & & \\
\hline $\begin{array}{l}\text { Con integridad acrosomal } \\
\text { con FITC-PSA }\end{array}$ & & $\begin{array}{c}0.7321^{2} \\
\mathrm{P}<0.0001\end{array}$ & \\
\hline $\begin{array}{l}\text { Vivos con integridad } \\
\text { acrosomal con FITC-PSA }\end{array}$ & & & $\begin{array}{c}0.6380^{1} \\
P=0.0002\end{array}$ \\
\hline
\end{tabular}

${ }^{1}$ Coeficiente de correlación de Pearson; ${ }^{2}$ Coeficiente de correlación de Spearman

Se determinó que entre 93 y $95 \%$ de espermatozoides presentaron el acrosoma íntegro cuando fueron evaluados utilizando FITC-PNA y FITC-PSA, respectivamente. Valores similares han sido reportados en alpacas al utilizar microscopía de fluorescencia (92\%; Morton et al., 2010) o citometría de flujo (88\%; Cheuqueman et al., 2013). Esta variable se caracterizó, además, por presentar un reducido intervalo de confianza y coeficiente de variación, no siguiendo la distribución normal. Estos resultados indicarían que un elevado porcentaje de espermatozoides epididimarios de alpaca tiene la capacidad de atravesar la zona pelúcida del ovocito durante la fecundación.

Con respecto a la viabilidad espermática, se encontró $60 \%$ de espermatozoides vivos cuando se utilizó la combinación FITCPNA/PI y $63 \%$ al evaluarlos con FITC-PSA/ PI. En trabajos previos, se ha descrito $80 \%$ de espermatozoides vivos de alpaca (Santiani et al., 2005) con semen colectado con vagina artificial. En este caso, el menor porcentaje de espermatozoides viables podría estar relacionado al tiempo transcurrido entre el beneficio de las alpacas con su evaluación en el laboratorio, así como a la técnica de recuperación de espermatozoides. También es interesante destacar el alto intervalo de confianza y coeficiente de variación.

En relación con la viabilidad e integridad acrosomal, se encontró 59 y $61 \%$ de espermatozoides vivos con acrosoma intacto utilizando FITC-PNA/PI y FITC-PSA/PI, respectivamente. Resultados ligeramente menores en espermatozoides epididimarios (49\%) y semen de alpaca (46\%) son reportados por Choez et al. (2014) y por Cheuqueman et al. (2013), respectivamente. Por otro lado, utilizando semen fresco colectado mediante vagina artificial, Santiani et al. $(2005,2013)$ reportan valores que van desde 78 a $45 \%$. Estas diferencias también han sido observadas en este estudio, dado que este parámetro presentó altos intervalos de confianza y coeficientes de variación. Se podría deducir que el menor porcentaje de espermatozoides viables con acrosoma intacto se debe principalmente al reducido porcentaje de espermatozoides viables y no al incremento del daño acrosomal. 
Las correlaciones significativas medias a altas obtenidas al comparar las dos lectinas en los tres parámetros estudiados indicarían que es posible utilizar cualquiera de ellas para el estudio de la integridad acrosomal en espermatozoides de alpaca.

\section{Conclusiones}

Es posible evaluar la integridad acrosomal en espermatozoides epididimarios de alpaca usando las lectinas Arachys hypogaea (PNA) y Pisum sativum (PSA) conjugadas con isoticianato de fluoresceína (FITC) mediante un citómetro de flujo con analizador de imágenes.

\section{Agradecimientos}

Esta investigación se realizó gracias al proyecto N. ${ }^{\circ} 123-F I N C y T-E C L-2014$ financiado por Innóvate Perú.

\section{Literatura Citada}

1. Banda J, Evangelista S, Ruiz L, Sandoval R, Rodríguez C, Valdivia M, Santiani A. 2010. Efecto de dilutores en base a tris, tes y leche descremada en la criopreservación de espermatozoides obtenidos del epidídimo de alpaca. Rev Inv Vet Perú 21: 145-153. doi: 10.15381/rivep.v21i2.129

2. Cardona W, Olivera M, Cadavid A. 2006. Evaluación de la reacción crosomal inducida por ionóforo de calcio: una aproximación más real de la capacidad fecundante del espermatozoide. Arch Esp Urol 59: 501-510.

3. Carretero MI, Fumuso F, Neild D, Giuliano S, Cetica P, Miragaya M. 2015. Evaluation of the acrosomal status in Lama glama sperm incubated with acrosome reaction inducers. Anim Reprod Sci 160: 1-11. doi: 10.1016/ j.anireprosci.2015.06.014
4. Celeghini E, Nascimiento J, Raphael C, Andrade A, Arruda R. 2010. Simultaneous assessment of plasmatic, acrosomal, and mitocondrial membranes in ram sperm by fluorescent probes. Arq Bras Med Vet Zootec 62: 536-543. doi: 10.1590/S0102-09352010000300006

5. Cheuqueman C, Merino O, Giojalas L, Von Baer A, Sánchez R, Risopatrón $J$. 2013. Assessment of sperm function parameter and DNA fragmentation in ejaculated alpaca sperm (Lama pacos) by flow cytometry. Reprod Domest Anim 48: 447-453. doi: 10.1111/rda.12096

6. Choez, K, Evangelista S, Santiani A. 2015. Comparación de las características seminales de las alpacas Huacaya y Suri. Spermova 5: 139-143. doi: 10.18548/aspe/0002.31

7. Fumuso F, Carretero M, Neild D, Miragaya M, Giuliano S. 2015. Evaluación de la viabilidad y el estado acrosomal de espermatozoides de llama (Lama glama). Resultados preliminares. En: I Congreso de la Sociedad Latinoamericana de Reproducción Animal. Buenos Aires, Argentina.

8. Gillan L, Evans G, Maxwell WM. 2005. Flow cytometric evaluation of sperm parameters in relation to fertility potential. Theriogenology 63: 445-457. doi: 10.1016/j.theriogenology.2004.09.024

9. Harrison R. 1998. Sperm evaluation: what should be testing? In: $6^{\text {th }}$ MAFF International Workshop on Genetic Resources. Tsukuba, Japan.

10. Hernández PJ, Fernández RF, Rodríguex SJ, Negrete RM, Soto MY, García $\boldsymbol{R} \boldsymbol{A}$. Efecto de la criopreservación de semen de conejo Nueva Zelanda (Oryctolagus cuniculus) sobre su viabilidad y estado acrosomal. Rev Salud Anim 34: 188-191.

11. Morton KM, Evans G, Maxwell WM. 2010. Effect of glycerol concentration, Equex STM suppelementation and liquid storage prior to freezing on the motility and acrosome integrity of frozen-thawed 
epididymal alpaca (Vicugna pacos) sperm. Theriogenology 74: 311-316. doi: 10.1016/j.theriogenology.2010.02.015

12. Patrat C, Serres C, Jouannet P. 2000. The acrosome reaction in human spermatozoa. Biol Cell.92: 255-266. doi: 10.1016/S0248-4900(00)01072-8

13. Risopatrón J, Peña P, Miska W, Sánchez R. 2001. Evaluation of the acrosome reaction in human spermatozoa: comparison of cytochemical and fluorescence techniques. Andrologia 33: 6367. doi: 10.1046/j.1439-0272.2001.-00405.x

14. Ramalho-Santos J, Schatten G, Moreno RD. 2002. Control of membrane fusion during spermiogenesis and the acrosome reaction. Biol Reprod 67: 10431051. doi: 10.1095/biolreprod.102.005967

15. Santiani A, Huanca W, Sapana R, Huanca T, Sepúlveda N, Sánchez $R$. 2005. Effects on the quality of frozen thawed alpaca (Lama pacos) semen using two different cryoprotectans and extenders. Asian J Androl 7: 303-309. doi: 10.1111/j.1745-7262.2005.00021.x
16. Santiani A, Evangelista S, Valdivia M, Risopatrón J, Sánchez R. 2013. Effect of the addition of two superoxide dismutase analogues (Tempo and Tempol) to alpaca semen extender for cryopreservation. Theriogenology 79: 842-846. doi: 10.1016/j.theriogenology.2012.12.012

17. Siciliano L, Marciano V, Carpino A. 2008. Prostasome-like vesicles stimulate acrosome reaction of pig spermatozoa. Reprod Biol Endocrinol 6: 5. doi: 10.1186/ 1477-7827-6-5

18. Silva P, Gadella B. 2006. Detection of damage in mammalian sperm cells. Theriogenology 65: 958-978. doi:10.1016/ j.theriogenology.2005.09.010

19. Ugarelli A, Evangelista S, Choez K, Pacheco J, Santiani A. 2015. Evaluación de diferentes concentraciones de FITC-PSA y FITC-PNA para la valoración de la integridad acrosomal en espermatozoides de alpaca. Spermova 5: 87-92. doi: 10.18548/aspe/0002.20 